\title{
Abdominal Subcutaneous Lipoma in a Mangalarga Marchador Horse
}

\author{
Bárbara de Barros, Hypólita Hellen Rodrigues de Souza, Solimar Felipe Contarini de Oliveira, \\ Tayná Bolsam da Silva, Ana Clara Santana Malegoni, Virgílio Zoppi Lemos, \\ Diogo Almeida Rondon, Luiz Alexandre Moscon Clairton Marcolongo-Pereira*
}

Faculty of Veterinary Science, Centro Universitário do Espírito Santo-UNESC, Colatina, ES, Brazil

Email: *clairton.marcolongo@terra.com.br

How to cite this paper: de Barros, B., de Souza, H.H.R., de Oliveira, S.F.C., da Silva, T.B., Malegoni, A.C.S., Lemos, V.Z., Rondon, D.A. and Marcolongo-Pereira, L.A.M.C. (2020) Abdominal Subcutaneous Lipoma in a Mangalarga Marchador Horse. Open Access Library Journal, 7: e6634.

https://doi.org/10.4236/oalib.1106634

Received: July 22, 2020

Accepted: August 9, 2020

Published: August 12, 2020

Copyright $\odot 2020$ by author(s) and Open Access Library Inc.

This work is licensed under the Creative Commons Attribution International License (CC BY 4.0).

http://creativecommons.org/licenses/by/4.0/

\begin{abstract}
Lipoma is a benign neoplasm characterized by the proliferation of well-differentiated adipocytes. The aim of the present study was to report a case of lipoma in the subcutaneous of a horse. A 5-year-old Mangalarga Marchador horse, weighing approximately $350 \mathrm{~kg}$, was referred to the Veterinary Hospital with a history of increased abdominal volume. On clinical examination, a well-defined and circumscribed mass was observed in the abdomen. Surgery was performed and the material was sent for histological examination. The diagnosis of lipoma was based on macroscopic and histological characteristics of the tumor. Subcutaneous lipomas in horses are relatively rare and when located in the abdomen they must be differentiated from hernia, eventration hematoma, seroma and abscess. Surgical excision is curative, even with incomplete excision of the mass.
\end{abstract}

\section{Subject Areas}

Veterinary Medicine

\section{Keywords}

Horse, Lipoma, Subcutaneous, Histopathology, Deferential Diagnosis

\section{Introduction}

Lipoma is a benign neoplasm characterized by the proliferation of well differentiated adipocytes. This tumor can occur in a wide variety of locations in animals, but is most often seen in subcutaneous tissue, usually as a lone mass [1]. In horses, lipomas correspond to $3 \%$ of neoplasms diagnosed in this species and occur more commonly in the intestinal mesentery [2] [3] and older 
animals are the most affected [4]. On the other hand, subcutaneous lipomas are rare neoplasm in horses, and when they appear, they affect more common animals under two years of age and can be found in the trunk and proximal limbs [5].

The cause of lipomas in animals is unknown. However, in human beings' translocations in $H M G A 1, H M G A 2$ e $L P P$ genes may be involved in the development of ordinary lipoma [6].

The diagnosis of lipoma is made by histopathological examination [7]. Stains for lipid, such as Oil-red-O, osmium, and Sudan black, on frozen tissue sections can assist in the diagnosis of this neoplasm [8]. Besides, lipomas and their subtypes are positives in the immunohistochemistry for vimentin and can be positive for S-100 [8]. These tumors have a good prognosis [9].

The aim of the present study was to report the occurrence of a case of abdominal subcutaneous lipoma in a Mangalarga Marchador horse, highlighting the main differential diagnoses of this neoplasm.

\section{Case Report}

A 5-year-old male Mangalarga Marchador horse weighing approximately $350 \mathrm{~kg}$ was referred to the Veterinary Hospital with a well-defined and circumscribed history of local abdominal volume increase (Figure 1A). In the anamnesis, the owner reported that the animal had this volume increase since he was 1 -year-old, and in the last 2 years the tumor progressed significantly in size. On physical examination, grade 4 of obesity was observed (scale from 1 to 5 ) and on palpation of the tumor, the animal did not have pain or discomfort. No hematological and biochemical changes were observed. On ultrasonography, it was observed a mass presenting hypoechogenicity with a coarse appearance and slightly heterogeneous with a hyperechogenic layer surrounding the tumor (Figure 1B). There are no signs of color Doppler flow. The tumor extended through the subcutaneous tissue and did not penetrate the abdominal cavity.

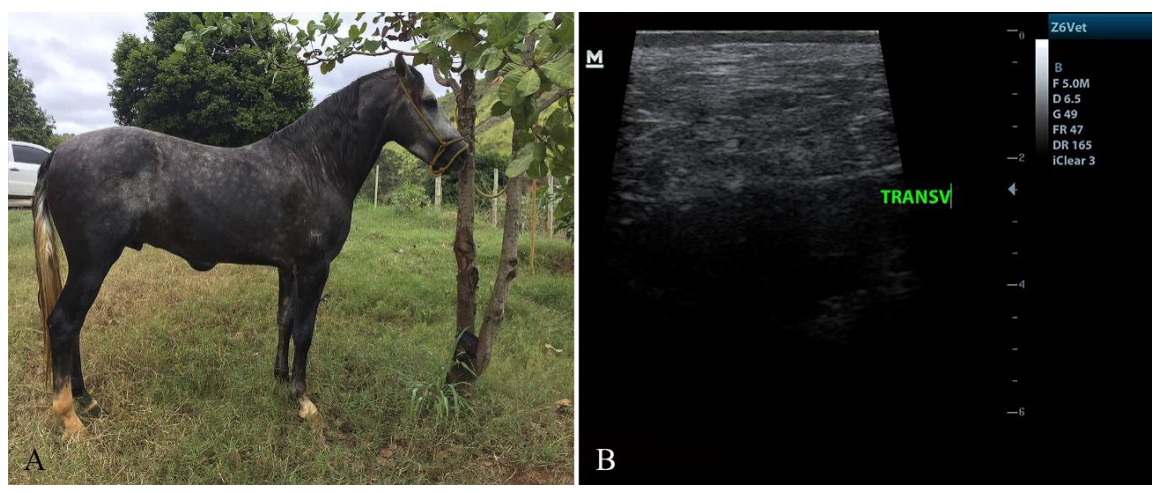

Figure 1. Abdominal subcutaneous lipoma in a Mangalarga Marchador. A: Note a well-defined and circumscribed local abdominal volume increase. B: Ultrasound image showing hypoechogenicity mass with coarse and slightly heterogeneous aspect with a hyperechogenic layer involving the tumor (2 - $5 \mathrm{MHz}$ linear transducer). 
Extraction of the mass was elected for treatment. Excision was performed with an elliptical incision with $3 \mathrm{~cm}$ from the mass margin. Divulsion was performed at the base of the mass that was under the abdomen and the entire neoplasia was removed. The skin was approached and sutured; and to decrease the tension, a subcutaneous suture (walking suture) was applied; after that, the subcutaneous tissue and the skin were closed with a simple continuous pattern. The removed mass was sent for histological analysis.

Macroscopically, the mass was $22 \times 12 \times 6 \mathrm{~cm}$, it was smooth and, on the cut was homogeneous white. In the histological analysis of the subcutaneous tissue and its expansion, compressing the underlying skeletal muscle was a well-circumscribed, partially encapsulated, moderately cellular neoplasm composed of mature adipocytes arranged in indistinct lobules on a fine fibrovascular stroma (Figure 2). Neoplastic adipocytes have distinct cell borders and a single clear vacuole (lipid) that compresses and peripheralizes a flattened and hyperchromatic nucleus. Anisocytosis is marked depending on vacuole size and anisokaryosis is minimal. Mitosis was not seen.

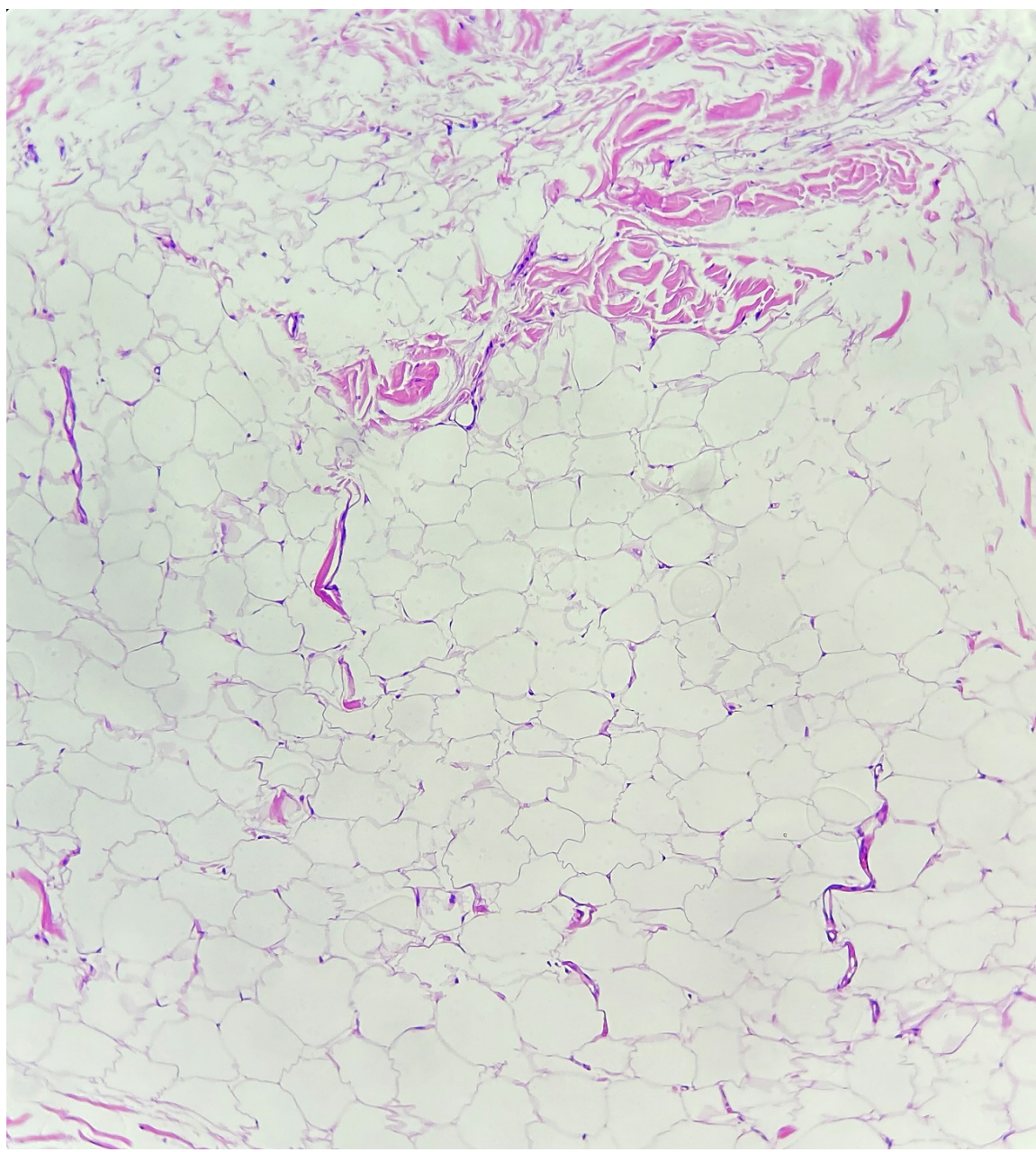

Figure 2. Abdominal subcutaneous lipoma in a Mangalarga Marchador. Photomicroscopy. Neoformation composed of mature adipocytes arranged in indistinct lobules on a fine fibrovascular stroma. Hematoxylin and Eosin, 10x. 


\section{Discussion}

The diagnosis of subcutaneous lipoma was based on the macroscopic and histological characteristics of the tumor. External lipomas are relatively rare tumors in horses, and they occur more in the limbs, thorax, abdominal wall, and eyelids [7]. In this case, the lipoma was in the animal's abdomen. Volume changes in this region must be differentiated from hernia, eventration, hematoma, seroma and abscess [10]. In this study, these changes were excluded by clinical examination and ultrasound. In a study on infiltrative lipoma, the authors mention that the cytology technique can also be used to differentiate lipomas from other lesions in the abdominal cavity [10]. Cytologic examination of lipomas reveals an often acellular preparation containing numerous lipid droplets and occasionally lipocytes. However, normal subcutaneous adipose tissue must be considered if samples is from fine needle aspiration.

Obese horses may have several comorbidities associated with this condition, such as: exercise intolerance, thermoregulatory inefficiency, abnormal reproductive performance and increased likelihood of developing lipomas [2] [11] [12] [13]. Probably, the obesity observed in the horse in this study favored the sudden growth of the subcutaneous lipoma observed.

Surgical excision is curative for lipomas and the prognosis for this neoplasm is favorable, even with incomplete excision of the mass. In this case the mass was completed excised and the horse was discharged from the hospital with the recommendation to return in 6-months to ensure the lipoma was not recurring. Follow-up communication with the owner 4 months after the surgery indicated that the horse had returned to full work and had had no known clinical signs since the surgical procedure.

\section{Conclusion}

Abdominal subcutaneous lipomas should be included in the differential diagnosis of hernias, eventration, hematoma, seroma, and abscesses. An ultrasound associated with other techniques can help to differentiate these diseases.

\section{Acknowledgements}

The authors thank the Fundação de Amparo à Pesquisa e Inovação do Espírito Santo (FAPES) and the Centro Universitário do Espírito Santo (UNESC) for supporting this study and for the scholarship.

\section{Conflicts of Interest}

The authors declare no conflicts of interest regarding the publication of this paper.

\section{References}

[1] Hendrick, M.J. (2017) Mesenchymal Tumors of the Skin and Soft Tissues. In: Meuten, D.J., Ed., Tumors in Domestic Animals, 5th Edition, John Wiley \& Sons Ltd., 
Inc., Ames, 158-160.

[2] Garcia-Seco, E., Wilson, D.A., Kramer, J., Keegan, K.G., Branson, K.R., Johnson, P.J. and Tyler, J.W. (2005) Prevalence and Risk Factors Associated with Outcome of Surgical Removal of Pedunculated Lipomas in Horses: 102 Cases. Journal of the American Association of Veterinary Medicine, 226, 1529-1537. https://doi.org/10.2460/javma.2005.226.1529

[3] Ludwig, E.K., Byron, C.R., Lahmers, K.K. and Santo, M.P. (2017) Frontal and Caudal Maxillary Sinus Lipoma in a Horse. The Canadian Veterinary Journal, 58, 503-507.

[4] Brosnahan, M.M. and Paradis, M.R. (2003) Demographic and Clinical Characteristics of Geriatric Horses: 467 Cases (1989-1999). Journal of the American Association of Veterinary Medicine, 223, 93-98. https://doi.org/10.2460/javma.2003.223.93

[5] Hammer, E.J., Chope, K., Lemire, T.D. and Reef, V.B. (2002) A Lipoma of the Extensor Tendon Sheaths in a Horse. Veterinary Radiology \& Ultrasound, 43, 63-65. https://doi.org/10.1111/j.1740-8261.2002.tb00445.x

[6] Nishio, J. (2011) Contributions of Cytogenetics and Molecular Cytogenetics to the Diagnosis of Adipocytic Tumors. Journal of Biomedicine and Biotechnology, 2011, 1-9. https://doi.org/10.1155/2011/524067

[7] Carr, E.A. (2019) Skin Condition Amenable to Surgery. In: Auer, J.A., Stick, J.A., Kummerle, J.M. and Prange, T., Eds., Equine Surgery, Elsevier, St Louis, 425-439. https://doi.org/10.1016/B978-0-323-48420-6.00028-4

[8] Gross, T.L., Ihrke, P.J., Walder, E.J. and Affolter, V.K. (2005) Skin Diseases of the Dog and Cat. 2nd Edition, Blackwell, Ames. https://doi.org/10.1002/9780470752487

[9] Viliotti, T.A.Z., Macedo, H.J.R., Chaves, M.G.L., Oliveira, R.C.R., Silva, H.F. and Ferraz, R.E.O. (2018) Giant Subcutaneous Lipoma in a Dog's Lumbosacral Region: Case Report. Pubvet, 12, 1-6. https://doi.org/10.22256/pubvet.v12n1a15.1-6

[10] Rebsamen, E., Gygax, D., Dennler, M., Jud, R. and Kummer, M. (2010) External Infiltrating Lipoma in a Two-Week-Old Foal: Computed Tomographic Evaluation for the Assessment of the Extension and Invasiveness of the Tumour. Equine Veterinary Education, 22, 602-607. https://doi.org/10.1111/j.2042-3292.2010.00137.x

[11] Henneke, D.R., Potter, G.D. and Kreider, J.L. (1983) Body Condition during Pregnancy and Lactation and Reproductive Efficiency of Mares. Theriogenology, 21, 897-909. https://doi.org/10.1016/0093-691X(84)90383-2

[12] Cymbalukm, N.F. and Christison, G.I. (1990) Environmental Effects on Thermoregulation and Nutrition of Horses. Veterinary Clinics of North América: Equine Practice, 6, 355-372. https://doi.org/10.1016/S0749-0739(17)30546-1

[13] Garlinghouse, S.E. and Burrill, M.J. (1999) Relationship of Body Condition Score to Completion Rate during $160 \mathrm{~km}$ Endurance Races. Equine Veterinary Journal Supplement, 30, 591-595. https://doi.org/10.1111/j.2042-3306.1999.tb05290.x 